\title{
Editorial
}

\section{Acuerdo con European Association of Urology para traducir guias clínicas}

\author{
En referencia al trabajo de este número que aparece en las páginas 113-126
}

\author{
José L. Ruiz Cerdá \\ Servicio de Urología. Hospital Universitario La Fe. Valencia, España
}

$\mathrm{E}$ los últimos años, la dirección de ACTAS ha estado encaminada a conseguir "tener factor de impacto". Para alcanzar este objetivo, se han llevado a cabo acciones estratégicas esenciales como la traducción al inglés, la inclusión del icono de artículo de libre acceso y el de "free full text" en PubMed, la actualización de la calidad formal de la revista a los estándares de las revistas internacionales o la publicación de mayor número de artículos de autores latinomamericanos, europeos y americanos. Estas medidas han convertido a ACTAS en una revista internacional, bilingüe español-inglés y de gran visibilidad y accesibilidad. Como consecuencia, en mayo del 2008, se recibió la notificación procedente del Institute for Scientific Information (ISI) de que ACTAS entraba a formar parte del Science Citation Index Expanded (SCI-E). De esta forma, el primer factor de impacto de la historia de ACTAS verá la luz a mediados del 2010.

Por otra parte, en el Congreso Nacional del 2008, la Confederación Americana de Urología acordó que ACTAS fuera su revista oficial.

Estos dos hechos decisivos han llevado a dar por concluida una etapa y dar comienzo a otra con objetivos diferentes. Por un lado, tenemos que conseguir el mayor factor de impacto posible. Por otro, hay que conseguir que la revista se convierta en el referente de la comunidad urológica hispanohablante. El primer objetivo significa obtener el mayor número de citaciones en revistas incluidas en el SCI-E. El segundo, significa principalmente captar el máximo de lectores y autores hispanohablantes.

La estrategia para conseguir citaciones está bien definida y se centra en dos acciones que se retroalimentan mutuamente: la publicación de artículos citables y política de obtención de citas. Dentro de la publicación de artículos citables se sabe que los meta-análisis, revisiones sistemáticas, ensayos clínicos randomizados, estudios cooperativos y guías de actuación o de grupos de consenso son artículos de referencia que proporcionan gran número de citaciones. La política de obtención de citas es más compleja y requeriría mayor explicación que la de esta editorial. Por otro lado, la estrategia para convertir ACTAS en revista referente de la comunidad hispanohablante estriba fundamentalmente en que sea útil para sus lectores y autores.

La revista European Urology publica periódicamen- te artículos resumen de las guías clínicas elaboradas por comités de expertos de la European Association of Urology (EAU). Estos artículos son extractos redactados en forma ágil y fácil de entender por lo que resultan muy atractivos por su utilidad. En este número de ACTAS se publica la guía clínica europea del cáncer de próstata traducida al español. Corresponde al artículo publicado en el volumen 53 del European Urology del 2008, páginas 68-80, con el título "EAU Guidelines on Prostate Cancer". Esta traducción es oficial y cuenta con el permiso de las Oficinas de Educación y de Guías Clínicas de la EAU así como del Comité Editorial del European Urology. Esto ha sido posible gracias a que se ha establecido una colaboración con la Oficina de Guías Clínicas para traducir los trabajos referidos a las guías clínicas ya publicadas así como las actualizaciones que se hagan en un futuro o la de nuevos trabajos. La dirección de ACTAS se compromete a proporcionar el artículo ya traducido para que quede disponible en la página web de la EAU.

La importancia que esta colaboración tiene para nuestra revista es doble y está claramente alineada con los objetivos estratégicos de la nueva etapa. En primer lugar, son artículos muy citables. Puesto que son la base de elaboración de cualquier trabajo. En segundo lugar, por el servicio que se da a todos aquellos urólogos para los que el idioma inglés aún supone una barrera.

Por lo tanto espero que, a partir de ahora, cuando se elabore un trabajo sobre cáncer de próstata, bien sea para ACTAS, otra revista nacional incluida en el SCI-E, o para cualquier revista en inglés, se cite la referencia del trabajo que aparece en este número. De esta forma, el beneficio será doble. Estaremos contribuyendo a la divulgación de las guías europeas a la vez que contribuimos a aumentar el factor de impacto de este proyecto común que se llama ACTAS.

Correspondencia autor: Dr. José L. Ruiz Cerdá

Servicio de Urología. Hospital Universitario La Fe Avda. Campanar 21 - 46009 Valencia. Tel.: 963862700

E-mail autor: Jose.L.Ruiz@uv.es

Información artículo: Editorial

Trabajo recibido: febrero 2009 